\title{
A safe signaling device for use in measuring consummatory behavior in the automated aversion therapy of alcoholics
}

\author{
ROBERT F. BREMSER, ROBERT S. DAVIDSON, and ROBERT M. MORTENSEN \\ Veterans Administration Hospital, Miami, Florida 93125
}

\begin{abstract}
This article describes an accurate device used for safely reporting a drinking consummatory response, for the purpose of delivering an electrical stimulus contingent upon that response. The article also gives a brief description of the possible hazards posed by the use of electronic sensing devices, and a detailed description of a shot glass engineered to avoid these complications, along with a record demonstrating its reliable use in an automated alcoholic conditioning program.
\end{abstract}

Alcoholism has been a continuing problem in this country and a cause of growing concern (Wilkinson, 1970). For this reason, we have devoted the last 10 years to developing and implementing new and more effective behavioral methods for its treatment, among which are techniques of aversive conditioning (Davidson, 1972 ; 1974; Note 1).

Solomon (1964) suggested that aversive stimuli may be more effective in suppressing consummatory behaviors such as eating or drinking than in suppressing instrumental behavior. However, few investigators have followed this up to date (Walker, Popovich, \& Derby, Note 2). This situation may have been the result of a lack of appropriate technical equipment used for the recording and measurement of consummatory responses, especially with human subjects.

Azrin and Holz (1966) suggest that aversive stimuli would be maximally effective when delivered as close as possible to the decelerative target behavior, especially to produce long-term treatment effects. This suggested the need for a device with which to measure and record the consummatory response, and thereby aid the development of a more effective treatment of alcoholism (Davidson, 1974). One possible solution might be an electronic sensing device, such as a drinkometer (GrasonStadler E4690A). However, such a sensing device would pose a possible safety hazard because the aversive stim. ulus, electric shock, is administered simultaneously with the drinking response. In a previous application with alcoholic subjects (Whaley \& Malott, 1968), a metal shot glass served as a sensing electrode when it touched

Reprint requests should be sent to Robert S. Davidson, Psychology Research (151), Veterans Administration Hospital, 1201 N.W. 16 Street, Miami, Florida 33125. The authors gratefully acknowledge the help of Leonard F. Helm and his staff in the Manual Arts Therapy Program at the Miami V.A. Hospital. We also wish to thank Robert N. Perkins for his invaluable assistance, and Elizabeth W. Henretig for excellent secretarial support. This study was supported by VA Project Grant 1777-01, Modification of Alcoholic Behavior, Robert S. Davidson, Principal Investigator. the lips of the subject. Rubber gloves served to insultate the glass so that the electrical information was not altered by contact with the subject's hand. In the event of a malfunction in the shock and/or the sensing circuitry, the results could be lethal; the current could be directed from the site of electrode placement (forearm or fingertips) to the subject's lips, thereby effecting a path of current flow through the chest (Butterfield, 1975). Our solution, then, hinged upon isolating an electrical signaling device in a plastic glass.

\section{CONSTRUCTION}

A shot glass was manufactured from a $2 \times 2 \times 4$ in. piece of Plexiglas stock turned down on a lathe to the specifications in Figure 1. The reservoir portion of the glass was cut out on the lathe by visual comparison with a standard shot glass.

Once the holes were drilled in the base, the glass was again placed on the lathe. Steel wool was used to initiate polishing on the inside and outside of the glass, followed by buffing with a cloth and jewelers' rouge until clear. The holes in the base were not polished, which hid the switch from view. A standard mercury-

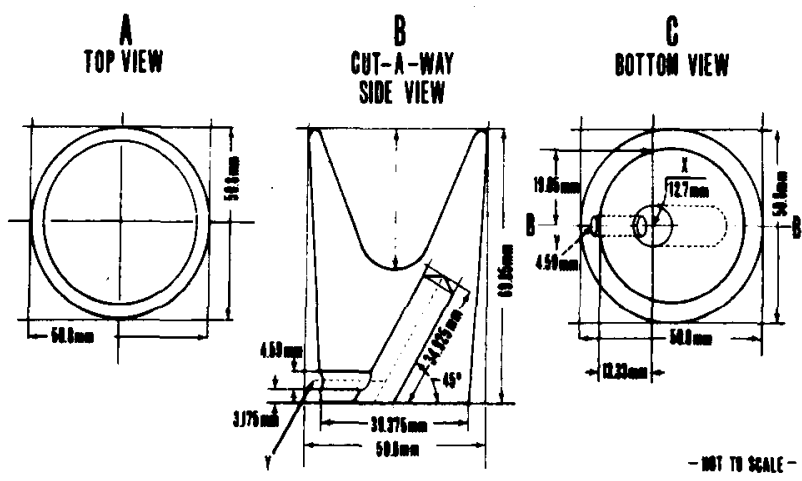

Figure 1. Shot glass, dissected view: (a) view from top, (b) side view cutaway, (c) bottom. In Figure 1c, point " $X$ " is the center of the 45-deg angle, 12.7-mm (1/2-in.) hole, and " $Y$ " is the center of the $4.59-\mathrm{mm}(3 / 16-\mathrm{in}$.) hole. 
wetted contact switch, approximately $25.4 \mathrm{~mm}$ long, was mounted in the larger inclined hole. Standard mercury switches are readily purchased from any of a number of electronic and/or hobby stores (e.g., Radio Shack, Olson's, etc.).

Care was taken to insure that the mercury switch would close only when the glass was tilted to an angle at which liquid would just begin to flow from the rim. At this point, it should be noted that we are delivering $2 \mathrm{cc}$ of alcohol per delivery. If larger amounts of liquid are to be used, the angle of the inclined hole should be increased accordingly. This could be roughly approximated by taping the mercury switch to the side of the glass and gauging the requisite angle. There is some builtin latitude here, as the $12.7-\mathrm{mm}$ hole allows for angular adjustment, due to the smaller diameter of the mercury switch. Small pieces of cotton readily take up the excess space and hold the switch in adjustment. Also, different manufacturers make different sized switches, allowing for considerable variation in the angular inclination of the switch in the hole, as well as differences in angle of the reservoir portion of the glass.

Next, small gauge coaxial cable was soldered to the switch leads. Our requirements dictated a wire approximately $1.5 \mathrm{~m}$ long, soldered to a miniature $1 / 8$-in. phono plug, which could then be inserted into the experimental console at a mating jack.

Finally, after adjustments were completed on switch activation angles and the components of the glass assembled, the base was capped and sealed with hot paraffin and allowed to cool. This sealed the components in place. A razor blade sufficed to trim the paraffin even with the base of the glass. Figure 2 represents the finished product.

\section{APPLICATIONS}

The glass functioned extremely well in one of our aversive conditioning paradigms used for alcoholic

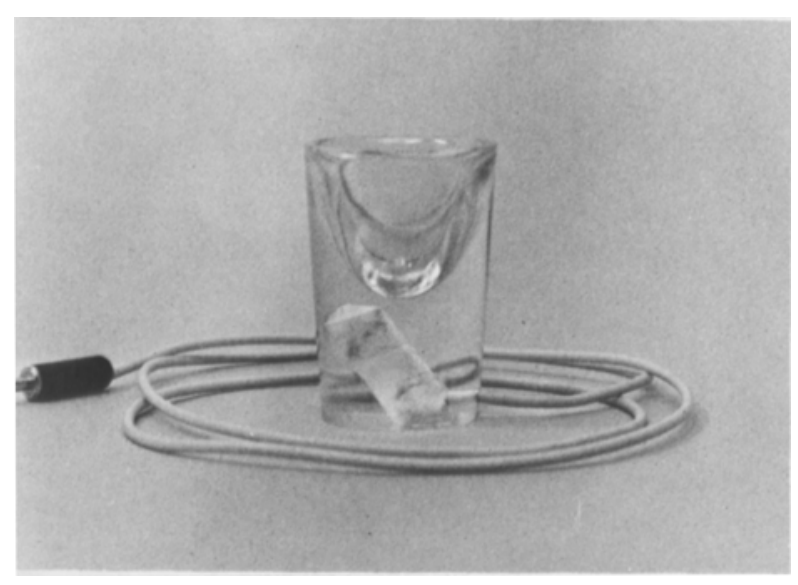

Figure 2. Photograph of finished glass with switch assembled.

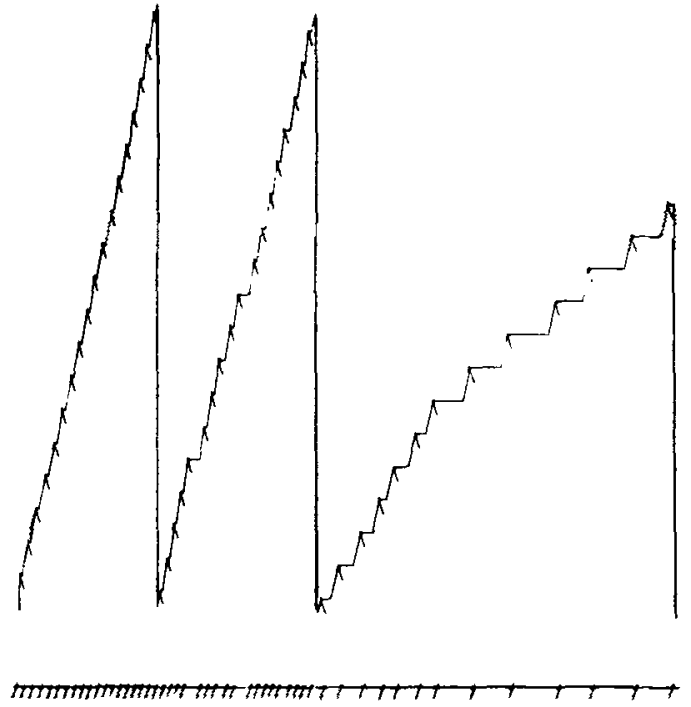

Figure 3. Cumulative records showing two different response rates for the same patient, utilizing the activated shot glass. Responses moved the upper pen upward, and the pen reset automatically following $\mathbf{5 5 0}$ responses. Hatch marks indicate reinforcement delivery. Offsets of the event pen on the lower record indicate shock delivery. Records show the reliability with which the shot glass signaled and, ultimately, delivered shocks.

patients. Each patient was seated facing a console containing a supply of alcohol, Lindsley manipulanda on which operant responses were made, the shot glass, and the mating jack. This equipment, as well as the patient, were contained in a sound-attenuated chamber (IAC403A). Twice daily, for $1 / 2-h$ sessions (morning and afternoon), the patient was permitted to respond to produce $2 \mathrm{cc}$ of alcohol following each 30th pull of the manipulandum. The apparatus was programmed so that the patient would have to drink each reinforcement before another could be delivered. Each patient in this study was given electric shock simultaneously with each reinforcement consumption, with the exception of the baseline and reversal (nontreatment) portions of the program. Figure 3 demonstrates the reliability with which the unit functioned to deliver shock only when the subject drank the liquid.

\section{CONCLUSIONS}

Although our signaling device was used specifically to deliver an aversive stimulus upon consumption of alcohol, this idea could be adapted to more general uses. With very few programming changes, it could be used as an automatic signal for any kind of liquid consumption studies with humans. The glass could also be further refined by the installation of a small transmitter at the base. A receiver operating a relay could be installed in the console and thereby eliminate the wire lead. Thus, the appearance of the glass would more closely approximate the natural environment of an alcoholic and perhaps enhance stimulus generalization. However, the glass 
in its present form is quite functional at a minimal expenditure.

\section{REFERENCE NOTES}

1. Davidson. R. S. Research design and the aversive con. ditioning of alcoholic behavior. Paper presented to the Southeastern Psychological Association, New Orleans, 1969.

2. Walker, L. C., Popovich, B. G., \& Derby, T. R. Intermittent and continuous punishment of operant and consummatory behaviors. Paper presented at the 81st Annual Convention of the American Psychological Association, Montreal, Quebec, Canada, 1973.

\section{REFERENCES}

Azrin, N. H., \& Holz, W. C. Punishment. In W. K. Honig (Ed.), Operant behavior: Areas of research and application. New York: Appleton-Century-Crofts, 1966.
Butterfield, W. H. Electric shock: Safety factors when used for the aversive conditioning of humans. Behavior Therapy, 1975, 6, 98-110.

Davidson, R. S. Modification of alcoholic behavior. $V . A$. New'sletter for Research in Psychology. 1972. 14, 30-31.

DAvidson, R. S. Alcoholism: Experimental analyses of etiology and moditication. In K. S. Calhoun, H. E. Adams, \& K. M. Mitchell (Ed.). Innovative treatment methods in psychopathology. New York: Wiley, 1974.

Solomon, R. L. Punishment. American Psychologist, 1964. 19. 239-253.

Whaley, D. L., \& Malott, R. W. Elementary principles of behavior. Kalamazoo, Mich: Behaviordelia, 1968.

Wilkinson, R. The prevention of drinking problems. New York: Oxford University Press. 1970.

(Accepted for publication June 17. 1976.) 